\title{
BASAL CELL CARCINOMA ARISING WITHIN A TRICHOEPITHELIOMA: AN IMMUNOHISTOCHEMICAL STUDY
}

\author{
BARTOS V.
}

Martin Biopsy Center, Ltd., Martin, Slovakia

\begin{abstract}
A b s t r a c t
Background: Trichoepithelioma (TE) and basal cell carcinoma (BCC) of skin represent distinct tumor entities but they have a close histogenetic and phenotypic relationship.

Objective: A unique case of a BCC arising within a TE is described with an emphasis on the analysis of different and for each tumor type typical immunophenotype.

Material and Methods: A 71-year-old man presented with a subcutaneous solid tumor in the lumbar region. The resected tumor specimen was studied by immunohistochemistry.

Results: Histology revealed a coexistence of classic TE and nodular BCC. Both tumors were strongly positive for BerEP4 and negative for EMA. Neoplastic epithelium of the BCC showed a diffuse staining for Bcl-2, while the TE expressed Bcl-2 almost exclusively in the peripheral cells of tumor islands. In the BCC, neoplastic nodules exhibited a focal staining for CD10, while the peritumorous stroma did not. In contrast, the TE showed a focal immunoreactivity for $\mathrm{CD} 10$ in the stromal cells around the neoplastic islands which were completely negative. The TE contained intratumorous CK20-labeled Merkel cells but they were not detected in the BCC. A stromal immunoreactivity for CD34 was found in both tumors. Proliferative activity (Ki-67) was slightly higher in the BCC than in the TE.

Conclusion: Although a concomitant presence of TE and BCC in the same skin lesion is a unique finding, it may be sometimes encountered in a biopsy practice. Pathologists should provide a careful histologic examination of the whole TE lesion with precise section sampling to unveil such possible association.
\end{abstract}

Keywords: basal cell carcinoma, trichoepithelioma, trichoblastoma, immunohistochemistry

\section{INTRODUCTION}

Trichoepithelioma (TE) is an adnexal skin tumor containing epithelial structures that show a certain degree of differentiation toward hair follicle $(1,2)$. The classic variant consists predominantly of uniform basaloid cells arranged in variably sized nests, trabeculae or cribriform patterns, situated in a background stroma of fibroblastic tissue $(1,2)$. Despite its historical usage, the term TE has disappeared from the latest WHO classification (3). Various types of benign tumors that originate from follicular germinative cell, including TE, have been recently included under the term trichoblastoma $(3,4)$. The concept of trichoblastoma has undergone considerable changes since the term was first proposed by Headington in 1970. The latest WHO classification (3) adopted the definition of trichoblastoma introduced by Ackerman as a generic term for a benign cutaneous tumor composed of follicular germinative cells.

Trichoblastoma is further divided into the following types: $(3,4)$

- nodular

- large (including pigmented)

- small (including adamantinoid)

Corresponding author: MUDr., PhDr. Vladimír Bartoš, PhD., MPH; e-mail: vladim.bartos@gmail.com (C) 2020 Vladimir Bartos

This work is licensed under the Creative Commons Attribution-NonCommercial-NoDerivs 4.0 License (https://creativecommons.org/licenses/by-nc-nd/4.0/) 
- retiform (giant solitary trichoepithelioma)

- cribriform (conventional trichoepithelioma)

- racemiform (inconventional trichoepithelioma)

- columnar (desmoplastic trichoepithelioma)

Since the name TE is still routinely used in biopsy practice, in the present article the author works with this term according to tradition.

TE exhibits many histopathologic features similar to those of basal cell carcinoma (BCC) $(1,2)$. Therefore, the correct diagnosis is very important because BCC is a locally aggressive malignant neoplasia $(1,2,5-7)$ while $\mathrm{TE}$ is a benign tumor with excelent prognosis $(1,2)$. As a consequence, they require different therapeutic strategy and clinical management. The main differential diagnostic features of both entities are illustrated in Table 1. (1, 4). Considering the histomorphologic similarities, differentiating between TE and BCC is diagnostically challenging and is often not possible without the use of immunohistochemistry. In problematic cases, pathologists usually apply Bcl-2, CD10, CD34, and CK20 immunohistochemical stains to disclose a correct diagnosis. Herein, a unique case of a BCC arising within a TE is described with an emphasis on the analysis of different and for each tumor type typical immunophenotype.

Table 1 Useful histological features for distinguishingd between basal cell carcinoma and trichoepithelioma. (loosely adapted from ref. 1,4)

\begin{tabular}{|c|c|}
\hline Trichoepithelioma & Basal cell carcinoma \\
\hline symmetry & asymmetry \\
\hline surrounding by a fibrous stroma & invasive growth \\
\hline $\begin{array}{l}\text { fibroblasts-like cell aggregates, similar to } \\
\text { a follicular papillae }\end{array}$ & $\begin{array}{l}\text { absence (or minimal presence) of a specific } \\
\text { follicular stroma }\end{array}$ \\
\hline retraction artefact rare & retraction artefact common \\
\hline solar elastosis absent or rare & solar elastosis marked \\
\hline horn cysts common & usually no horn cysts \\
\hline usually no ulceration & often ulceration \\
\hline mitoses not increased & increased mitoses \\
\hline
\end{tabular}

\section{CLINICAL HISTORY}

A 71-year-old man presented with a subcutaneous solid tumor in the right lumbar region. He claimed that the lesion had been present for 3-4 years. Recently, it has become painful. Clinically, it appeared as a subcutaneous nodular resistence measuring a few centimeters. A presumptive clinical diagnosis was a lipoma. A surgical exstirpation of the lesion was done and the sample was send for a microscopic examination.

\section{MATERIAL AND METHODS}

The resected tumor mass consisted of a few fragments of solid tissue, brownish in color and elastic in consistency. The obtained specimen was processed into four formalin-fixed paraffin-embedded tissue blocks which were then stained with hematoxy- 
lin-eosin. The selected section was analyzed immunohistochemically with monoclonal mouse anti-human antibodies against the following antigens: EpCAM (clone BerEP4, DAKO, ready to use), EMA (clone E29, DAKO, ready to use), Bcl-2 (clone 124, DAKO, ready to use), CD10 (clone 56C6, DAKO, ready to use), CD34 (clone QBEnd/10, DAKO, ready to use), CK20 (clone Ks20.8, DAKO, ready to use), and Ki-67 (clone MIB1, DAKO, ready-to-use).

\section{RESULTS}

Microscopic examination of the sample revealed a coexistence of classic TE and nodular BCC (Figure 1). The dominant tumor component (> 95\% of total tissue) was the TE showing a characteristic histomorphologic growth pattern. It composed of small branching islands of basaloid cells with focal invaginations that somewhat resembled hair papillae. Nodular BCC consisted of typical nests of basaloid cells with peripheral nuclear palisading
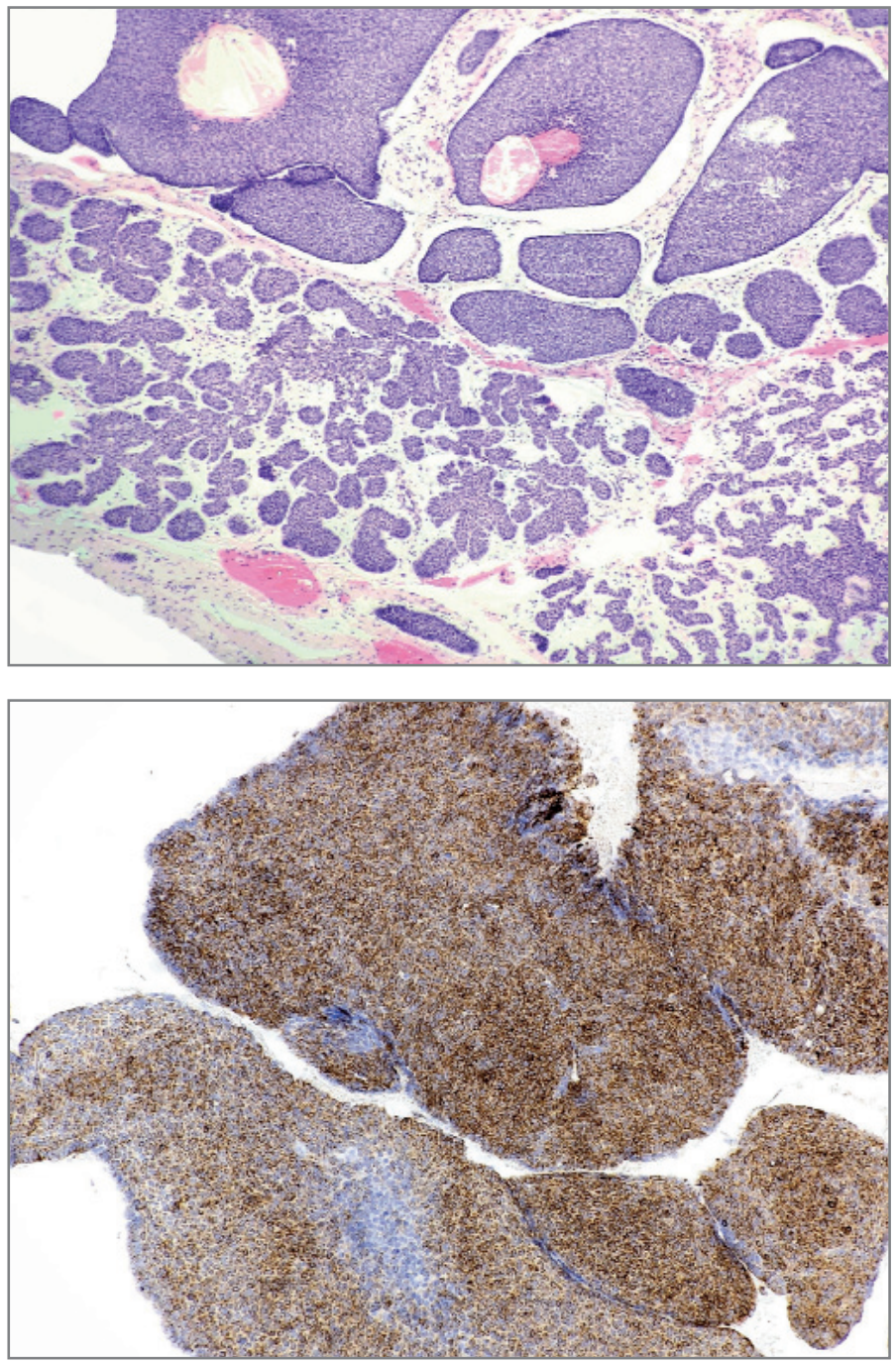

Fig. 1 Detail on interface between the trichoepithelioma (lower part) and the nodular basal cell carcinoma (upper part). (hematoxylin \& eosin, 40x)

Fig. 2 Basal cell carcinoma. Strong diffuse positivity for Bcl-2 in the neoplastic nodules. (80x) 
and clefting between tumor and stroma. No intact skin or another tissue was found. By immunohistochemistry, both tumors were strongly positive for BerEP4 and negative for EMA. Neoplastic epithelium of the BCC showed a diffuse staining for Bcl-2 (Figure 2), while the TE expressed Bcl-2 almost exclusively in the peripheral cells of tumor islands (Figure 3). In the BCC, neoplastic nodules exhibited a focal staining for CD10 (Figure 4), while the peritumorous stroma did not. In contrast, the TE showed a focal immunoreactivity for $\mathrm{CD} 10$ in the stromal cells around the neoplastic islands which were completely negative (Figure 5). The TE contained scattered intratumorous CK20-labeled Merkel cells (Figure 6). They were not detected in the BCC. A very strong immunoreactivity for CD34 in the peritumorous stroma was found both in the TE (Figure 7) and in the BCC. Proliferative activity (Ki-67 index) was slightly higher (up to $10 \%$ ) in the BCC (Figure 8 ) than in the TE $(<5 \%)$ (Figure 9). Since the lesion was obviously not completely removed, re-excision was recommended. At the time of writing this article no further clinical information about the patient was available.

Fig. 3 Trichoepithelioma. Expression of Bcl-2 predominantly in the outermost layers of tumor nests. (120x)
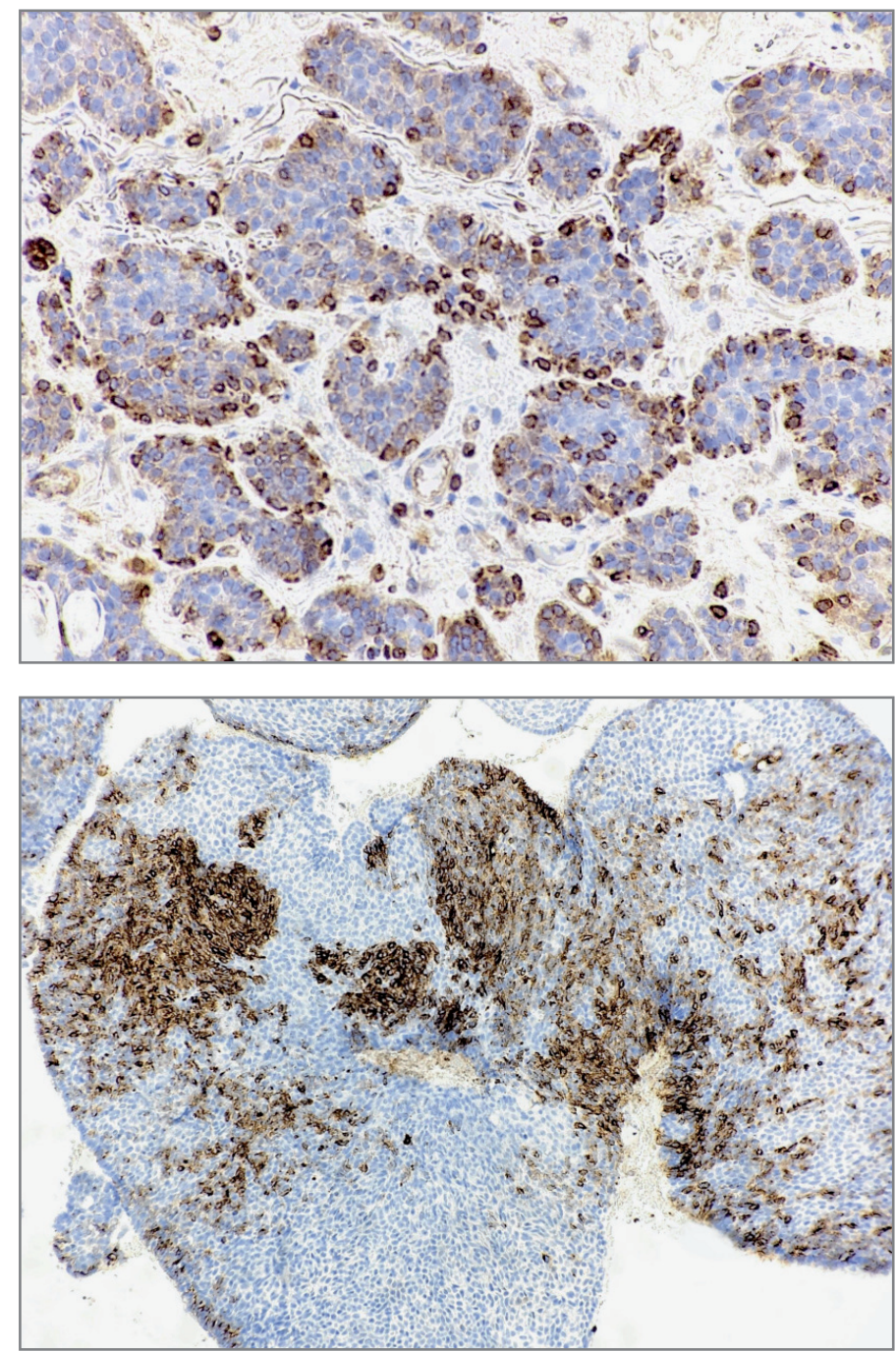

Fig. 4 Basal cell carcinoma. Focal positivity for CD10 in the neoplastic nodules. (80x) 

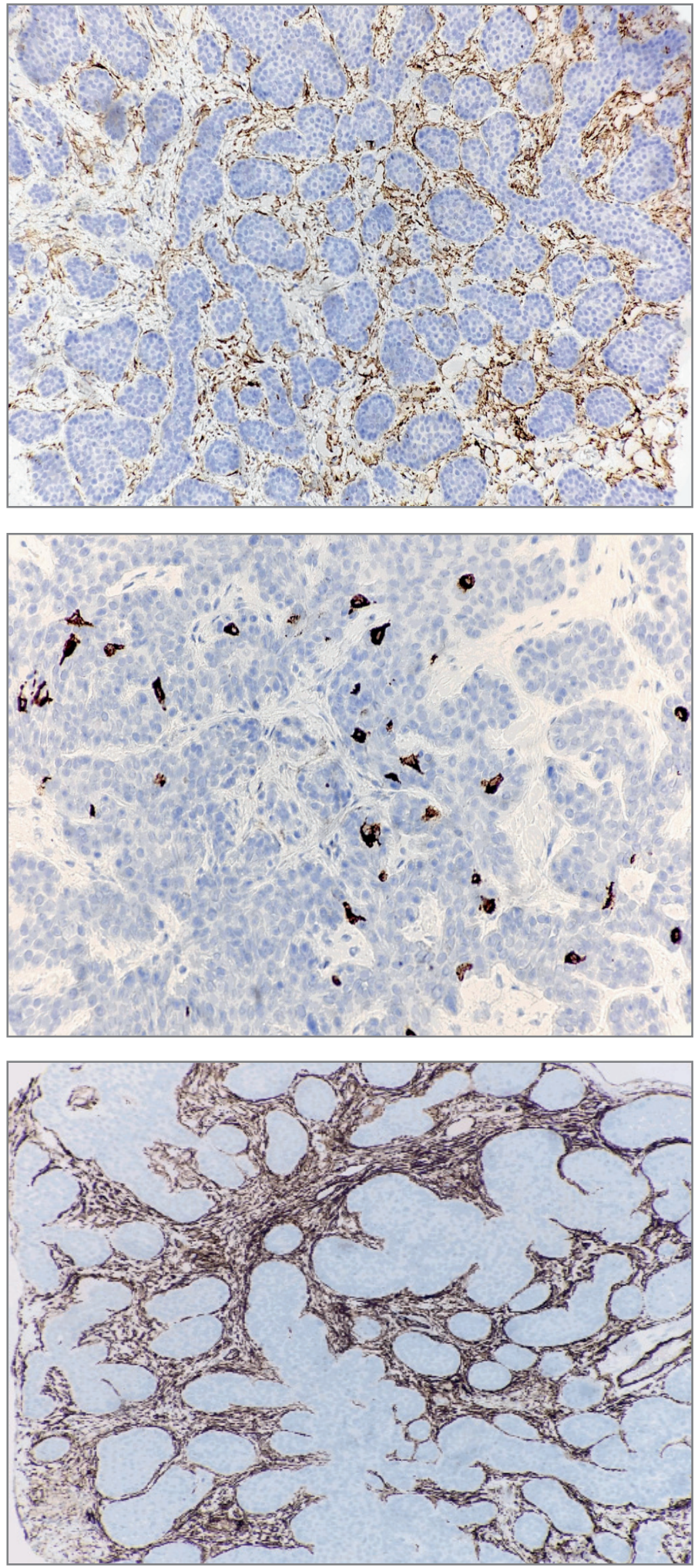

Fig. 5 Trichoepithelioma. Focal positivity for CD10 in the peritumorous stroma. (100x).

Fig. 6 Trichoepithelioma. Scattered CK20-positive Merkel cells in the tumor. (120x)

Fig. 7 Trichoepithelioma. Strong CD34 positivity in the peritumorous stroma. (100x ) 
Fig. 8 Basal cell carcinoma. Slightly increased Ki-67 proliferative index. (80x)

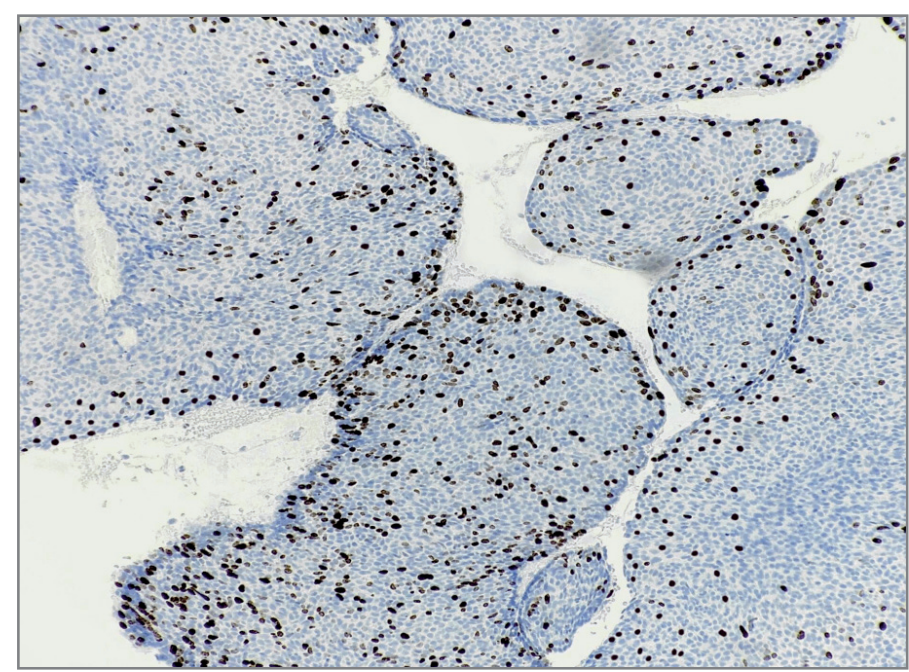

Fig. 9 Trichoepithelioma. Low Ki-67 proliferative index. (100x)

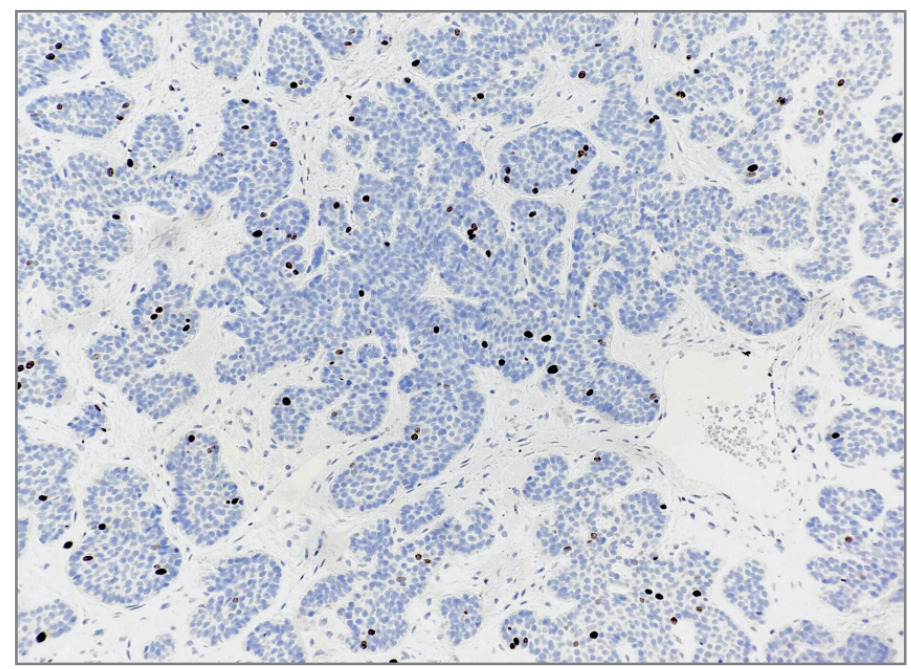

\section{DISCUSSION}

Although TE and BCC of skin represent distinct tumor entities with different biological behaviour, they have a close histogenetic and phenotypic relationship (2). It has been explained on the basis of an assumption that they have a common genesis from pluripotential cells which may develop toward hair structures (2). This hypothesis is supported by the fact that patched gene mutations are seen in both tumors (2). As it has already been mentioned, the pathologic distinction between them is sometimes complicated by many histomorphologic similarities $(1,2)$. As such, immunohistochemical analysis and adequate tissue sampling are essential in diagnostically equivocal lesions. In a routine biopsy practice several molecular markers are helpful in distinguishing TE from BCC (Table 2). (1,8-11). In the current case we analyzed a panel of selected antibodies to demonstrate an immunophenotypic diversity of these neoplasms. Our results corroborate the data found in the global literature which are summarized in Table 2. The only exception was a stromal staining of CD34 in the BCC, although it was not surprising because it developed in a background of 
the TE. In spite of that, the present case is an excelent example to demonstrate a typical immunoprofile of these two neoplasms. One should keep in mind, however, among those markers there is not a single one that is absolutely effective in discriminating between TE and BCC (12). This highlights the need to use a complex panel of antibodies to improve the differential diagnosis process.

Table 2 Standard immunohistochemistry panel for differential diagnosis of trichoepithelioma and basal cell carcinoma. (loosely adapted from ref. 1,8-11). (CK, cytokeratin; AR, androgen receptor; MC, Merkel cells, PHLDA1, pleckstrin homology - like domain family; p75NTR, p75 neurotrophin receptor)

\begin{tabular}{|l|l|l|}
\hline Marker & Trichoepithelioma & Basal cell carcinoma \\
\hline Bcl-2 & positive in peripheral tumor cells & diffusely positive in tumor nests \\
\hline CD10 & $\begin{array}{l}\text { - positive in stroma } \\
- \text { usually negative in tumor }\end{array}$ & $\begin{array}{l}\text { - usually positive in tumor } \\
- \text { negative in stroma }\end{array}$ \\
\hline CD34 & positive in stroma & negative \\
\hline Ki-67 & low & increased \\
\hline CK15 & focally positive & negative \\
\hline CK20 & focally positive (MC) & negative \\
\hline stromelysin-3 & negative & usually positive in stroma \\
\hline AR & negative & usually positive in tumor \\
\hline D2-40 & usually positive in tumor & usually negative in tumor \\
\hline PHLDA1 & positive in tumor & negative in tumor \\
\hline p75NTR & positive in tumor & usually negative in tumor \\
\hline
\end{tabular}

Very rarely, a BCC may develop within a TE in which case features of both tumors are seen in the same lesion. Only a few such cases have been published in literature until now (13-18). The concomitant occurrence of TE and BCC raises the question of whether there is a true malignant transformation or if it is only the result of two neoplasms independently developing in the same location (collision tumor) $(16,17)$. In our case it is unclear whether the BCC developed independently or by transformation from the TE. Considering a long-term growth of tumor containing just a small proportion of BCC component it seems more likely that this event represents a focal malignant transformation. Anyway, they were two histologically and immunophenotypically separate tumor units within a single lesion, of which the BCC was prognostically more important and should be decisive for further clinical management.

\section{CONCLUSION}

Although a concomitant presence of trichoepithelioma and basal cell carcinoma in the same skin lesion is a unique finding, it may be sometimes encountered in a biopsy practice. Pathologists should provide a careful histologic examination of the whole trichoepithelioma lesion, especially in large sized tumors, with precise section sampling to unveil such possible association. 
Acknowledgement: The author greatly thank MUDr. Ján Gumančík (pathologist, MBC, Martin), who initially diagnosed this case and Ing. Zuzana Kviatkovská (head of immunohistochemical laboratory, MBC, Martin) for her technical assistance.

\section{REFERENCES}

1. Alsaad KO, Obaidat NA, Ghazarian D. Skin adnexal neoplasms - part 1: an approach to tumours of the pilosebaceous unit. J Clin Pathol 2007;60(2):129-144.

2. Elder DE, Elenitsas R, Johnson BL, Jr, Murphy GF, Xu X (Eds). Lever's histopathology of the skin. 10th edition, Baltimore, Lippincott, Williams \& Wilkins, 2008.

3. Elder DE, Massi D, Scolyer R, Willemze R (Eds). WHO Classification of skin tumours. 4th Edition. Lyon, IARC; 2018. ISBN978-92-832-2440-2

4. Kazakov DV, Michal M, Kacerovska D, Mc Kee PH. Cutaneous adnexal tumors. Philadelphia, Wolters Kluwer/Lippincott, Williams \& Wilkins; 2012. ISBN 978-1-60547-854-8

5. Bartos V, Adamicova K, Pec M. Aggressive-growth types of basal cell carcinoma of the skin. Acta Medica Martiniana 2009;9(3):24-32.

6. Smolarova M, Minarikova E. Dermoscopy as a valuable tool in diagnosis of nodular amelanotic melanoma and nodular basal cell carcinoma. Acta Medica Martiniana 2017;17(1):21-27.

7. Kozarova A, Minarikova E, Pappova T. Practical use of high-resolution $20 \mathrm{MHZ}$ ultrasonography in dermatovenerology. Acta Medica Martiniana 2016;16(3):22-31.

8. Park J, Kim Y, Park JB , Park K, Chung H. Immunohistochemical evaluation of CD10, podoplanin (D2-40), and Ki-67 expression in basaloid epidermal proliferation of nevus sebaceous with comparative analysis of basal cell carcinoma and trichoepithelioma. Int J Clin Exp Pathol 2016;9(7): 7188-7194.

9. Astarci HM, Gurbuz GA, Sengul D, Hucumenoglu S, Kocer U, Ustun H. Significance of androgen receptor and CD10 expression in cutaneous basal cell carcinoma and trichoepithelioma. Oncol Lett 2015;10(6):3466-3470.

10. Plaza JA, Ortega PF, Bengana C et al. Immunolabeling pattern of podoplanin (d2-40) may distinguish basal cell carcinomas from trichoepitheliomas: a clinicopathologic and immunohistochemical study of 49 cases. Am J Dermatopathol 2010;32(7): 683-687.

11. Krahl D, Sellheyer K. p75 Neurotrophin receptor differentiates between morphoeic basal cell carcinoma and desmoplastic trichoepithelioma: insights into the histogenesis of adnexal tumours based on embryology and hair follicle biology. Br J Dermatol 2010;163(1):138-145.

12. Tebcherani AJ, de Andrade HF Jr, Sotto MN. Diagnostic utility of immunohistochemistry in distinguishing trichoepithelioma and basal cell carcinoma: evaluation using tissue microarray samples. Mod Pathol 2012;25(10):1345-1353.

13. Greywal T, Rubin AG, Jiang B. A rare presentation of basal cell carcinoma arising within trichoepithelioma: A diagnostic challenge. Cureus 2019;11(8):e5401.

14. Melly L, Lawton G, Rajan N. Basal cell carcinoma arising in association with trichoepithelioma in a case of Brooke-Spiegler syndrome with a novel genetic mutation in CYLD. J Cutan Pathol 2012;39(10):977-978.

15. Johnson SC, Bennett RG. Occurrence of basal cell carcinoma among multiple trichoepitheliomas. J Am Acad Dermatol 1993;28(2 Pt2):322-326.

16. Martinez CA, Priolii DG, Piovesan H, Waisberg J. Nonsolitary giant perianal trichoepithelioma with malignant transformation into basal cell carcinoma: report of a case and review of the literature. Dis Colon Rectum 2004;47(5):773-777.

17. Wallace ML, Smoller BR. Trichoepithelioma with an adjacent basal cell carcinoma, transformation or collision ? J Am Acad Dermatol 1997;37(2 Pt 2):343-345.

18. Pincus LB, McCalmont TH, Neuhaus IM, Kasper R, Oh DH. Basal cell carcinomas arising within multiple trichoepitheliomas. J Cutan Pathol 2008;35(Suppl 1):59-64. 